\title{
Analysis of the surface labelling characteristics of human spermatozoa and the interaction with anti-sperm antibodies*
}

\author{
R. J. Aitken, M. J. Hulme, C. J. Henderson, T. B. Hargreave $\ddagger$ and A. Ross $\dagger$ \\ MRC Units of Reproductive Biology and + Clinical and Population Cytogenetics and \\ $\ddagger$ Department of Urology, University of Edinburgh, U.K.
}

\begin{abstract}
Summary. Washed ejaculated human spermatozoa were surface labelled with ${ }^{125} \mathrm{I}$, using solid phase (iodogen) or enzymic (lactoperoxidase) methods, while membrane components possessing terminal galactose or galactosamine residues were labelled with the galactose oxidase-sodium $\left[{ }^{3} \mathrm{H}\right]$ borohydride technique. All three procedures revealed the presence of 2 major labelled surface components. The first comprised a broad band of radioactivity migrating just behind the ion front on SDS-PAGE, which could be extracted with chloroform and methanol, suggesting a lipid-like composition. The second fraction exhibited properties consistent with a major glycoprotein component of the human sperm plasma membrane, giving a peak of radioactivity with $M_{\mathrm{r}}=20000$, within which a discrete doublet of bands $\left(M_{\mathrm{r}}=17000\right.$ and 19000$)$ could be resolved by autoradiography. A more detailed analysis of the labelled protein fraction after TCA precipitation revealed a number of other surface components, the major ones of which exhibited $M_{\mathrm{r}}$ values of $30000,45000,66000,115000$ and 160000 .

Western blot analysis was then used to determine whether any of the surface components described above interacted with the $\gamma$-globulin fraction of antisera obtained from patients exhibiting idiopathic autoimmunity against sperm antigens. Using a purified membrane preparation as the target, antibodies were detected against numerous high molecular weight bands with $M_{\mathrm{r}}$ values similar to the major components of the human sperm surface $(35000,45000,66000,90000$ and 150000$)$. The nature of the antigens targeted by these antisera did not correlate with the ability of the latter to stimulate or suppress sperm-oocyte fusion.
\end{abstract}

\section{Introduction}

The biological functions of the mammalian spermatozoon depend heavily upon the properties of the plasma membrane, which must not only control the passage of ions into the interior of the cell (Bradley \& Forrester, 1980; Ashraf et al., 1982; Breitbart \& Rubinstein, 1983) but must also interact with constituents of the female genital tract in order to activate those mechanisms responsible for capacitation and the induction of the acrosome reaction (O'Rand, 1977; Ebenshade \& Clegg, 1980; Voglmayr et al., 1980). The sperm plasma membrane is also involved in two independent cell recognition events associated with the process of fertilization. The first involves the attachment of the spermatozoon to the surface of the zona pellucida, as a result of modifications to the sperm surface which take place in the epididymis (Saling, 1982; Shur \& Hall, 1982). The second event concerns the capacity of the equatorial segment of the sperm head to recognize and fuse with

\footnotetext{
*Address for reprints: Dr R. J. Aitken, MRC Unit of Reproductive Biology, Centre for Reproductive Biology, 37 Chalmers Street, Edinburgh EH3 9EW, U.K.
} 
the vitelline membrane of the oocyte, as a result of changes in the sperm plasma membrane which occur concomitant with the acrosome reaction (Yanagimachi, 1981).

In a clinical context, analysis of the human sperm plasma membrane is of importance in both the development of new approaches to immunocontraception (Aitken, 1982) and in understanding the nature and origins of idiopathic autoimmunity directed against sperm antigens (Poulsen \& Hjort, 1981; Lee et al., 1982; Naaby-Hansen \& Bjerrum, 1985).

Despite the fundamental and clinical importance of this research area, there have been very few formal studies concerning the composition of the human sperm surface and the nature of the components targeted by autoantibodies capable of disrupting human sperm function (Young \& Goodman, 1980; Dor et al., 1981). In the present study we have sought to extend our knowledge of this area by using a variety of membrane isolation and surface labelling techniques to determine the nature and orientation of the major constituents of the human sperm plasma membrane. Western blot analysis was then used to determine which of these membrane components interact with antisperm autoantibodies, previously characterized for their ability to influence human sperm function in vitro.

\section{Materials and Methods}

Semen donation. Human spermatozoa were collected from healthy donors exhibiting normal semen profiles ( $>20 \times 10^{6}$ spermatozoa $/ \mathrm{ml},>40 \%$ progressive motility and $>40 \%$ normal morphology) into sterile plastic containers. After allowing at least $30 \mathrm{~min}$ for liquefaction to occur the spermatozoa were separated from seminal plasma by 3 cycles of centrifugation and resuspension in 8-mi volumes of Medium BWW (Biggers et al., 1971). The final sperm pellet was resuspended in $1 \mathrm{ml}$ Medium BWW, analysed to determine the concentration of spermatozoa using an improved Neubauer haemocytometer and finally diluted to a concentration of $20 \times 10^{6} \mathrm{cells} / \mathrm{ml}$.

Anti-sperm antibodies. Antisera were obtained from patients exhibiting infertility associated with idiopathic autoimmunity against sperm antigens. The Tray Agglutination Test (TAT) was used to detect the presence of antisperm antibodies in samples of heat-inactivated $\left(56^{\circ} \mathrm{C}\right.$ for $\left.30 \mathrm{~min}\right)$ blood serum. The assay was performed according to the protocol described by Friberg (1974) with the minor modifications introduced by Jager et al. (1978). Serially diluted heat-inactivated samples were incubated with donor spermatozoa in microchamber trays under paraffin oil at $37^{\circ} \mathrm{C}$ and the results were read after $2 \mathrm{~h}$ using an inverted microscope.

The presence of antisperm antibodies was also assessed using immunobeads coated with anti-human $\operatorname{lgG}$ or $\lg \mathrm{A}$ (Biorad Laboratories, Watford, Herts). To perform this assay $200 \mu \mathrm{l}$ of a donor sperm suspension $\left(10 \times 10^{6}\right.$ cells $\left./ \mathrm{ml}\right)$ were incubated with $20 \mu \mathrm{l}$ heat-inactivated antiserum for $3 \mathrm{~h} ; 5 \mu \mathrm{l}$ of this preparation were then mixed with $5 \mu$ l of the washed immunobeads on a microscope slide and incubated for $10 \mathrm{~min}$ before examination by phase-contrast microscopy.

Sperm function tests. The ability of human spermatozoa, obtained from 12 individual donors, to recognize and fuse with the vitelline membrane of the oocyte was assessed using the zona-free hamster egg penetration test (Yanagimachi et al., 1976) following the induction of the acrosome reaction wih A23187 (Aitken et al., 1984). The $\gamma$-globulin fraction from each autoimmune antiserum was isolated by sodium sulphate precipitation (Aitken $e t$ al., 1982) to yield preparations containing $5 \mathrm{mg} \gamma$-globulin $/ \mathrm{ml}$. These preparations were then incubated at a dilution of 1:10 with spermatozoa $\left(20 \times 10^{6} / \mathrm{ml}\right)$ for $1 \mathrm{~h}$ before the addition of A23187, prepared as an aqueous suspension of the $\mathrm{Ca}^{2+} / \mathrm{Mg}^{2+}$ salt $(0.026 \mathrm{mg} / \mathrm{ml}$; Aitken et al., 1984). After a further incubation period of $2 \mathrm{~h}$ the spermatozoa were pelleted by centrifugation at $500 \mathrm{~g}$ for $5 \mathrm{~min}$ and resuspended in Medium BWW at a concentration of $10 \times 10^{6} / \mathrm{ml}$. At this point in the procedure, the percentage of motile spermatozoa was estimated with the aid of a grid on an eye-piece graticule. Zona-free hamster oocytes were then introduced into these sperm suspensions and after $3 \mathrm{~h}$ they were scored for the presence of decondensing sperm heads with an attached or closely associated tail. Control incubations contained the same concentration of $\gamma$-globulin from non-immune donors.

The influence of the antisera on the ability of human spermatozoa to penetrate human cervical mucus was assessed using the procedure described by Katz et al. (1980) as modified by Aitken et al. (1985).

Isolation of membrane vesicles. Sperm samples were prepared as described above and resuspended in $1 \mathrm{mM}$-EDTA (pH 5.0) containing a protease inhibitor, 1 mm-phenylmethyl sulphonyl fluoride (PMSF; Sigma, MO, U.S.A.). The sperm membranes were detached using an ultrasonicator (Soniprep, MSE, Crawley, Sussex, U.K.) using $3 \times 10-$ sec bursts, with a probe amplitude of $3 \mu \mathrm{m}$, keeping the tube on ice between bursts to minimize heating effects. This sonication protocol was established experimentally using several different combinations of probe amplitude and durations of treatment, assessing the degree of plasma membrane removal and cell disruption by electron microscopy.

The ultrasonicated suspension was centrifuged at $500 \mathrm{~g}$ to pellet the intact spermatozoa and the supernatant was again centrifuged at $3000 \mathrm{~g}$ to remove any residual cells. The supernatant was removed and centrifuged at $100000 \mathrm{~g}$ for $1 \mathrm{~h}$ on an ultracentrifuge (Sorvall OTD-50 Du Pont Instruments, Stevenage, Herts, U.K.) to yield a crude membrane preparation. After the method of Gillis et al. (1978) for the preparation of human sperm plasma membranes. 
the crude membrane pellet was resuspended in $0.25 \mathrm{M}$-sucrose and layered onto a discontinuous sucrose gradient $(1.57 \mathrm{M}, 1.3 \mathrm{M}, 1.0 \mathrm{M}$ sucrose) and centrifuged at $100000 \mathrm{~g}$ for $2 \mathrm{~h}$. The membrane fraction was collected as a discrete layer at the 1.0 M-sucrose interface, diluted in Dulbecco's phosphate-buffered saline (PBS; Flow Labs, Irvine, U.K.) and again centrifuged at $100000 \mathrm{~g}$ to pellet the membranes. According to Gillis et al. (1978) the membrane fraction collected from the $1.0 \mathrm{M}$-sucrose interface derives from the plasma membrane in view of its ultrastructural appearance, sedimentation rate, high $5^{\prime}$-nucleotidase and low succinic dehydrogenase activities. We have also found that this fraction is enriched in NADPH oxidase activity, which is indicative of the plasma membrane. These preparations were stored at $-20^{\circ} \mathrm{C}$ before solubilization in sample buffer for sodium dodecyl sulphate-polyacrylamide gel electrophoresis (SDS-PAGE).

The ultrastructural appearance of the sperm pellets and isolated membrane fractions was evaluated after fixation with $5 \%$ glutaraldehyde in cacodylate buffer and post-fixation in $1 \%$ osmium tetroxide.

Surface labelling of intact spermatozoa. To identify the externally orientated components of the human sperm plasma membrane, various surface labelling procedures were used with intact cells.

Exposed tyrosine residues were iodinated with the solid-phase reagent 1,3,4,6-tetrachloro-3 $\alpha, 6 \alpha$-diphenylglycoluril (Iodogen: Pierce Chemical Company, Rockford, IL, U.S.A.), according to the method of Fraker \& Speck (1978) and Markwell \& Fox (1978). Typically, $10^{7}$ spermatozoa in $100 \mu$ l PBS were added to a glass tube plated with $100 \mu \mathrm{g}$ Iodogen, and exposed to $500 \mu \mathrm{Ci} \mathrm{Na}{ }^{125}$ (Amersham, Bucks, U.K.) for $10 \mathrm{~min}$, agitating the tube occasionally. The reaction was stopped by the addition of excess $0.25 \mathrm{M}-\mathrm{KI}$ and the iodinated spermatozoa were centrifuged (500 $\mathrm{g}$ ) and washed 3 times in PBS to remove unlabelled iodine. The surface label was solubilized by the addition of $0.5 \mathrm{ml} 1 \%$ Triton X-100, containing $10 \mathrm{~mm}$-Tris- $\mathrm{HCl}, 1 \mathrm{~mm}$-EDTA, and $1 \mathrm{mM}$-PMSF (pH 8.0) for $30 \mathrm{~min}$ at $4^{\circ} \mathrm{C}$. The residual sperm pellet was removed by centrifugation, and the supernatant containing the surface label was stored at $4^{\circ} \mathrm{C}$ before analysis by gel electrophoresis.

Enzymic iodination of the sperm surface was achieved with lactoperoxidase and adapted from the method described by Young \& Goodman (1980), using $10^{7}$ spermatozoa and $100 \mu \mathrm{g}$ lactoperoxidase/ml, activated by the addition of $10 \times 20 \mu \mathrm{l}$ samples of $9 \times 10^{-5 \%}(\mathrm{v} / \mathrm{v})$ hydrogen peroxide at $15-\mathrm{sec}$ intervals. The reaction was stopped by the addition of excess $0.25 \mathrm{M}-\mathrm{KI}$ and the labelled sperm surface was solubilized as described above.

Surface labelling of terminal galactose or galactosamine residues was achieved by the procedure described by Gahmberg \& Hakomori (1973) and Steck \& Dawson (1974). In brief, $1 \mathrm{ml}$ of $10^{7}$ spermatozoa in PBS was treated with 40 i.u. galactose oxidase (Sigma, MO, U.S.A.) and incubated for $30 \mathrm{~min}$ at $37^{\circ} \mathrm{C}$, after which $0.5 \mathrm{mCi} \mathrm{NaB}\left[{ }^{3} \mathrm{H}\right]_{4}$ (Amersham, Bucks, U.K.) was added, and the mixture was incubated for a further $20 \mathrm{~min}$ at $37^{\circ} \mathrm{C}$. The reaction was terminated by the addition of excess PBS, the labelled preparations were washed to remove excess $\mathrm{NaB}\left[{ }^{3} \mathrm{H}\right]_{4}$ and solubilized as before. To account for non-specific incorporation of tritium, galactose oxidase was omitted from control incubations of spermatozoa.

Label fractionation. To remove any radiolabelled lipid or glycolipid components from the above preparations (Teuscher et al., 1982; Klinefelter \& Hamilton, 1985) the ${ }^{125} \mathrm{I}$ labelled material was fractionated by the addition of 4 volumes of chloroform/methanol mixture $(2: 1 \mathrm{v} / \mathrm{v})$ to one volume of solubilized label in a glass tube, mixing thoroughly. After the mixture had settled, precipitated protein was removed from the interface between the chloroform and methanol and rewashed with the same solvent mixture. The chloroform phases were combined, dried down under nitrogen, and both this material and the precipitate were independently solubilized in sample buffer before SDS-PAGE.

The proteins were also precipitated by the addition of $40 \%$ ice-cold trichloroacetic acid (TCA) to the solubilized label to give a final concentration of $10 \% \mathrm{TCA}$ in the mixture. After incubation for $30 \mathrm{~min}$ at $4^{\circ} \mathrm{C}$, the precipitate containing the labelled proteins/glycoproteins was pelleted by centrifugation at $500 \mathrm{~g}$ for $20 \mathrm{~min}$ at $4^{\circ} \mathrm{C}$. The precipitate was rewashed in $10 \%$ TCA, centrifuged again and finally washed with an ethanol:ether mixture $(1: 1, \mathrm{v} / \mathrm{v})$. The organic phase was dried down as before and both this and the precipitate fraction were prepared for electrophoresis. Protein determinations were carried out using the technique of Lowry et al. (1951).

SDS-polyacrylamide gel electrophoresis ( $S D S-P A G E$ ). SDS-PAGE was performed according to the method of Laemmli (1970) using a Protein 1 electrophoresis cell (Bio Rad Labs, Watford, U.K.). The stacking gel was composed of $3.5 \%$ acrylamide, while the resolving gel contained $10 \%$ or $12 \%$ acrylamide. Labelled, or unlabelled samples, and known molecular weight standards were run under reducing conditions, using 2-mercaptoethanol (5\%, v/v) as the reducing agent, and bromophenol blue as indicator. Electrophoresis was performed at a constant current of $60 \mathrm{~mA}$ through the stacking gel, then at $30 \mathrm{~mA}$ through the resolving gel, for $2-3 \mathrm{~h}$, after which the gels were silver stained (Biorad, Watford, Herts, U.K.). For the radiolabelling experiments the sample tracks were carefully cut up into 2 mm sections, and for the ${ }^{125} \mathrm{I}$-labelled material, the individual slices were counted in a multihead gamma counter (Nuclear Enterprises NE 1600) in $63 \times 11 \mathrm{~mm}$ plastic tubes (Sarstedt, Leicester, U.K.). The tritiated gel slices had first to be solubilized with the tissue solubilizer NCS (Amersham, Bucks, U.K.), each slice being incubated with $1.0 \mathrm{ml}$ of a $10 \%$ NCS solution for $2 \mathrm{~h}$ at $50^{\circ} \mathrm{C}$. For certain experiments gels containing the iodinated samples were silver stained before autoradiography ( X -Omat-AR film: Kodak, Manchester, U.K.).

Immunoblotting. The Western blotting experiments were carried out according to the method of Towbin et al. (1979) using a Trans Blot cell and a 160/1.6 Model power pack (Bio-rad, Watford, Herts, U.K.). The transfer buffer

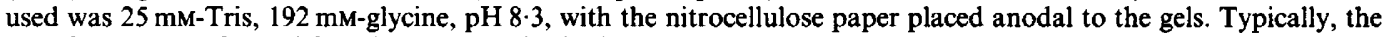
transfers were performed for $3 \mathrm{~h}$ at $60 \mathrm{~V}$ and $0.25 \mathrm{~A}$.

The antigens used in these experiments $(20-50 \mu \mathrm{g} /$ track) were either TCA precipitates of purified sperm membrane 
vesicles or whole sperm samples treated with $1 \%$ deoxycholate (BDH, Glasgow, U.K.) for $1 \mathrm{~h}$ at $4^{\circ} \mathrm{C}$ and then TCA precipitated as previously described. These materials were produced from samples provided by a randomly selected panel of 60 donors exhibiting normal semen profiles. The purpose of the deoxycholate treatment was to solubilize not only the sperm plasma membrane, but also to release internal antigens, to investigate whether the auto-antibodies were, in part, directed against such components. For these studies the $\gamma$-globulin fractions from control and autoimmune antisera were used at a concentration of $0.17 \mathrm{mg} / \mathrm{ml}$ in Tris-buffered saline $(20 \mathrm{~mm}$-Tris, $500 \mathrm{mM}-\mathrm{NaCl}, 3 \%$ gelatin, $\mathrm{pH}$ 7.5).

\section{Results}

\section{Surface labelling studies}

Analysis of the surface components labelled by the Iodogen method revealed the presence of 2 major radiolabelled peaks; a broad area of radioactivity just behind the ion front and a discrete peak of radioactivity with an $M_{\mathrm{r}}$ value of 20000-24 000 (Fig. la). Analysis of the surface components labelled with the lactoperoxidase technique revealed a similar pattern (Fig. 1b). In this case, however, the peak with a $M_{\mathrm{r}}$ of 20000-24000 was diminished in size relative to the leading peak, possibly because the lactoperoxidase method is a slightly more vectorial labelling technique than the Iodogen procedure. The galactose oxidase method produced a labelling pattern similar to that seen with lactoperoxidase, with a heavily labelled leading peak followed by a relatively minor component with an $M_{\mathrm{r}}$ value of 20000-24000 (Fig. 1c). In control studies in which the galactose oxidase was omitted from the incubation mixture the minor peak was not labelled although some non-specific labelling of the component trailing behind the ion front was still observed.

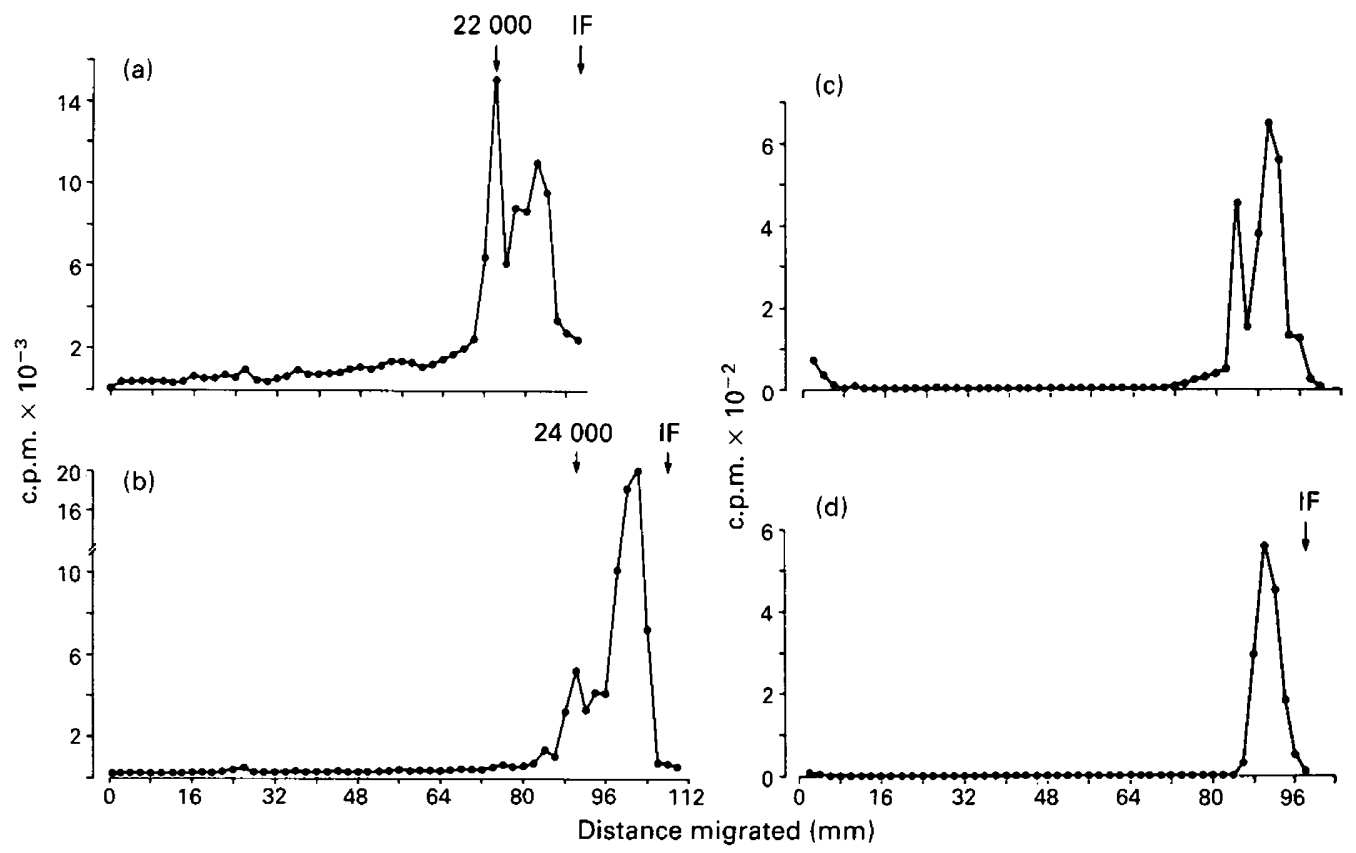

Fig. 1. Electrophoretic profile of the labelled components of the human sperm surface as resolved on $10 \%$ polyacrylamide gels. (a) ${ }^{125} \mathrm{I}$-labelling with the Iodogen method; (b) ${ }^{125} \mathrm{I}$ labelling with the lactoperoxidase technique; (c) ${ }^{3} \mathrm{H}$-labelling with the galactose oxidase$\mathrm{NaB}\left[{ }^{3} \mathrm{H}\right]_{4}$ technique; and (d) ${ }^{3} \mathrm{H}$-labelling with $\mathrm{NaB}\left[{ }^{3} \mathrm{H}\right]_{4}$ omitting galactose oxidase. IF = ion front. 


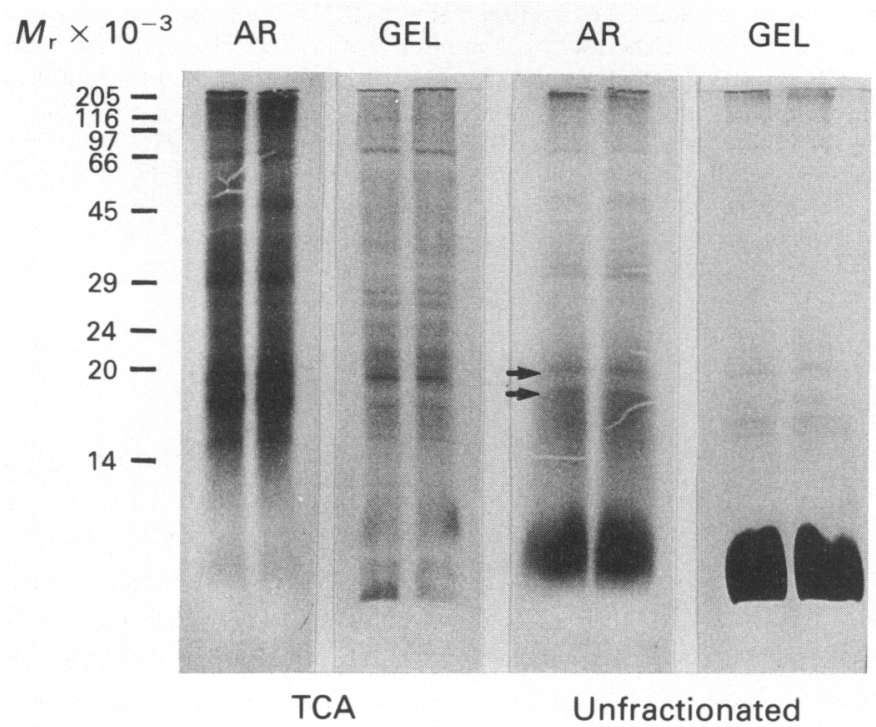

Fig. 2. Stained preparations and autoradiographs of surface components labelled with the Iodogen technique. Unfractionated $=$ unfractionated labelled preparation; TCA $=$ TCA precipitated, ether-washed material; $\mathrm{AR}=$ autoradiograph; $\mathrm{GEL}=$ silver-stained track of extracted proteins. Arrows indicate doublet of labelled components with $M_{\mathrm{r}}$ values of 19000 and 17000 . Molecular weights of the standards are indicated.

Further resolution of the surface labelled components was obtained by autoradiography of the labelled preparations. These studies (Fig. 2) revealed, in addition to the large mass of labelled material migrating behind the ion front, that the labelled components migrating with an $M_{\mathrm{r}}$ of around 20000 contained a discrete doublet of bands with $M_{\mathrm{r}}$ values of 19000 and 17000 respectively. Autoradiography also revealed the presence of additional minor bands including a doublet of $M_{\mathrm{r}} 30000$, a broad band at $M_{\mathrm{r}} 40000-45000$, and a discrete band at $M_{\mathrm{r}} 66000$, in addition to high molecular weight components migrating near the origin of the gel. When the autoradiographs were compared with silver stained gels of the same preparations, distinct differences were noted indicating the selective nature of the surface labelling procedure. For example, the stained preparations revealed a doublet of bands with $M_{\mathrm{r}} 15000$ and 16000 , which were not represented on the autoradiographs and hence represent major membrane constituents with little exposure on the outer surface of the membrane. Conversely, other components, such as the doublet of bands at $M_{\mathrm{r}}$ 30000 , were not visualized on the stained gels but were clearly represented on the autoradiographs, suggesting the presence of minor membrane constituents with an external orientation (Fig. 2).

The major component of the sperm surface migrating behind the ion front probably has a lipidlike composition since it could be readily removed by organic solvents (Figs $2 \& 3$ ). The TCA precipitation technique was subsequently used to concentrate the labelled protein fraction and hence resolve the many minor surface-orientated components on the sperm plasma membrane (Figs 2 \& 4). This analysis confirmed that the major components of the human sperm surface, after lipid extraction, include a broad area of radioactivity with a peak of $M_{\mathrm{r}} 20000$ incorporating a discrete doublet of bands at $M_{\mathrm{r}} 19000$ and 17000 , a second doublet with an $M_{\mathrm{r}}$ value of 30000 , a broad band of $M_{\mathrm{r}} 40000-45000$, a major constituent at $M_{\mathrm{r}} 66000$ and high molecular weight bands at $M_{\mathrm{r}} 115000$ and 160000 . In addition there were minor constituents with $M_{\mathrm{r}}$ values of $15000,25000,27000,35000,78000$ and 90000 . Once again Fig. 2 reveals the selective nature of the surface labelling procedure in that components which were heavily labelled, such as the band at 


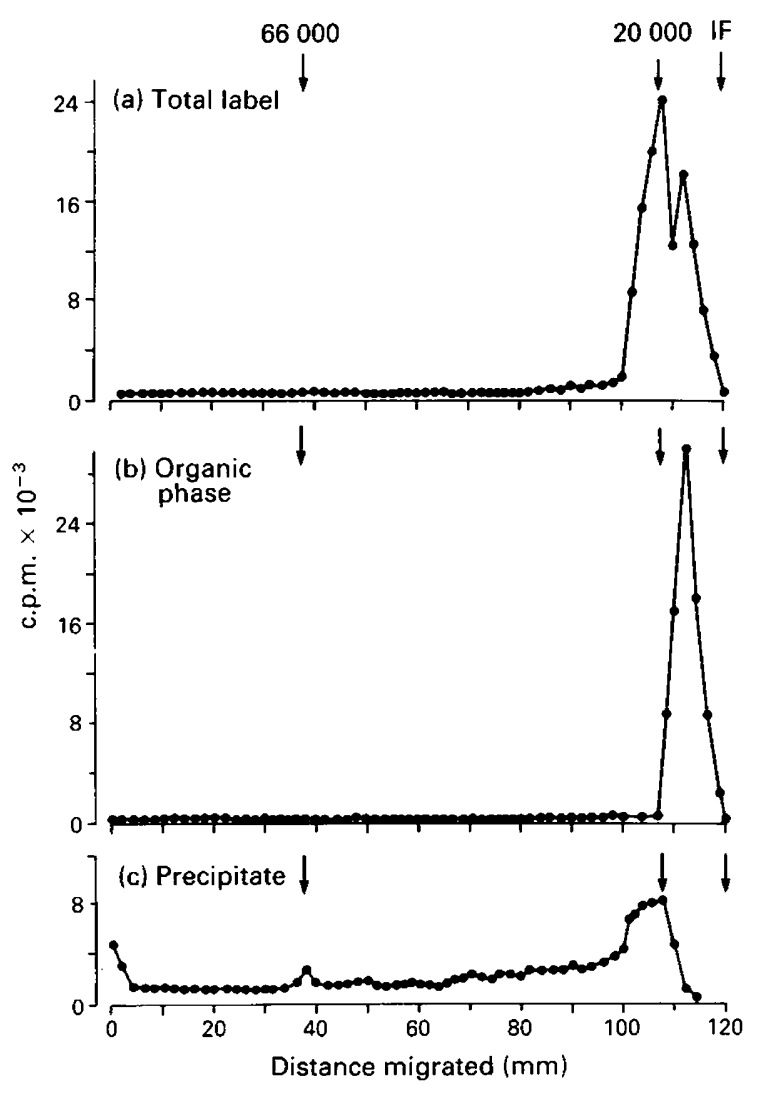

Fig. 3. Electrophoretic profile of the ${ }^{125}$ I-labelled components of the human sperm surface following the Iodogen procedure and resolution on $10 \%$ polyacrylamide gels: (a) profile of the total labelled pool, (b) profile of the material extracted by chloroform and methanol, and (c) profile given by the precipitated protein. $I F=$ ion front.

$M_{\mathrm{r}} 40000-45000$, were not evident on the silver-stained gels, while certain proteins which featured in the stained preparations (e.g. the bands at $M_{\mathrm{r}} 28000,24000$ or 16000 ) were not detectable on the autoradiographs.

\section{Preparation of human sperm membrane fraction}

Ultrastructural examination of the spermatozoa after ultrasonication revealed the effective loss of the sperm plasma membrane, dispersal of the acrosomal contents and partial removal of the outer acrosomal membrane. Other structures in the spermatozoa, including the mitochondria and flagellar apparatus, appeared to remain largely in association with the cells and were brought down in the $500 \mathrm{~g}$ and $3000 \mathrm{~g}$ pellets. The $100000 \mathrm{~g}$ pellets contained a mixture of electron-dense flocculent material, presumably derived from the interior of the acrosome, and membranes, which were frequently vesiculated. These vesicles were of 2 types: occasional electron-dense vesicles, possibly deriving from the outer acrosomal membrane, judging from their ultrastructural appearance (Silvestroni et al., 1980), and a large number of distended or collapsed vesicles composed of material resembling the plasma membrane of the intact cell. After sucrose density centrifugation a homogeneous membrane preparation was produced composed of the latter type of membrane, in the form of sheets, whorls and vesicles with diameters ranging from 0.5 to $3.5 \mu \mathrm{m}$ (Fig. 5). 


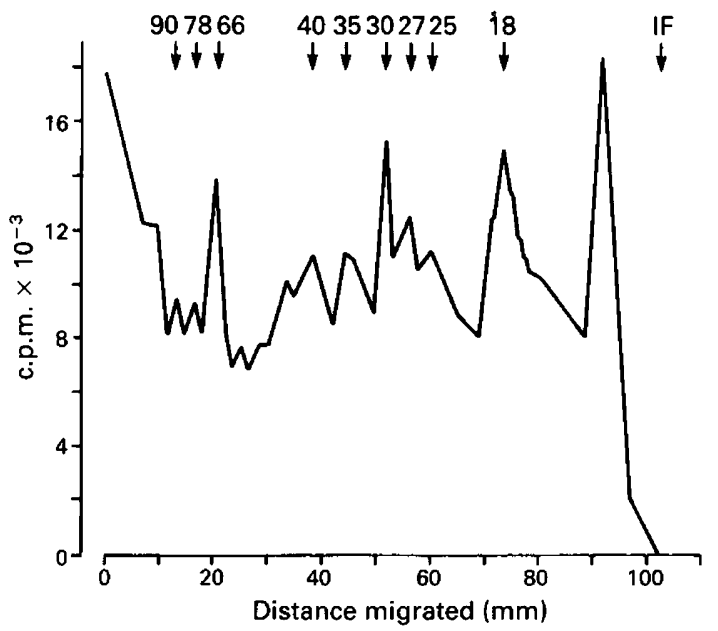

Fig. 4. Electrophoretic profile of TCA-precipitated ${ }^{125}$ I-labelled components of the human sperm surface following the Iodogen procedure and resolution on $10 \%$ polyacrylamide gels. Molecular weights $\left(\times 10^{-3}\right)$ of markers are indicated. If $=$ ion front.
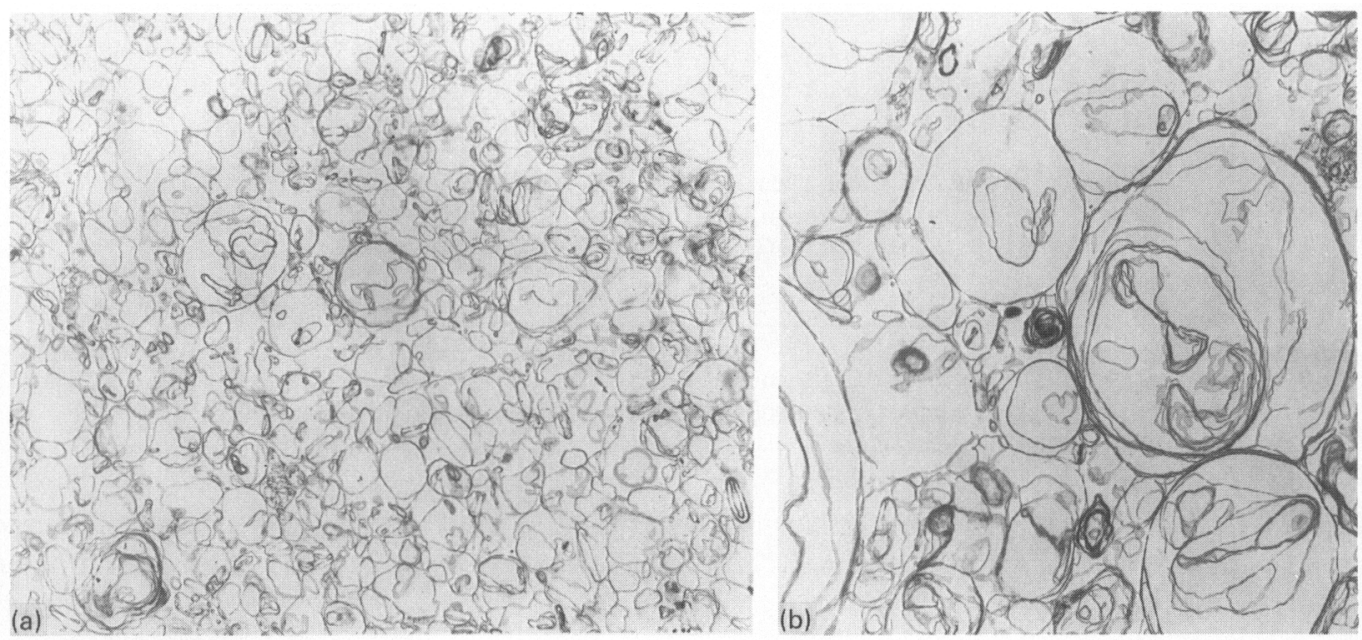

Fig. 5. Electronmicroscopy of sperm membrane preparations showing a homogeneous population of sheets and vesicles. $\times 23760$.

Analysis of these membrane preparations by SDS-PAGE revealed an electrophoretic profile which was very similar to that seen in the surface labelling studies (Fig. 6), the major constituents exhibiting the same apparent $M_{\mathrm{r}}$ values as the surface-labelled components $(15000,17000,19000$, $25000,30000,66000,115000$ and 160000 ). In addition, some minor components were present in these gels, which were not detected in the surface-labelling studies, and presumably represent membrane proteins which do not have external orientation.

\section{Interaction between the sperm surface and antisperm antibodies}

The anti-sperm antisera $(n=61)$ were first characterized for their ability to affect sperm function in vitro, with particular reference to the ability of acrosome-reacted spermatozoa to recognize and 


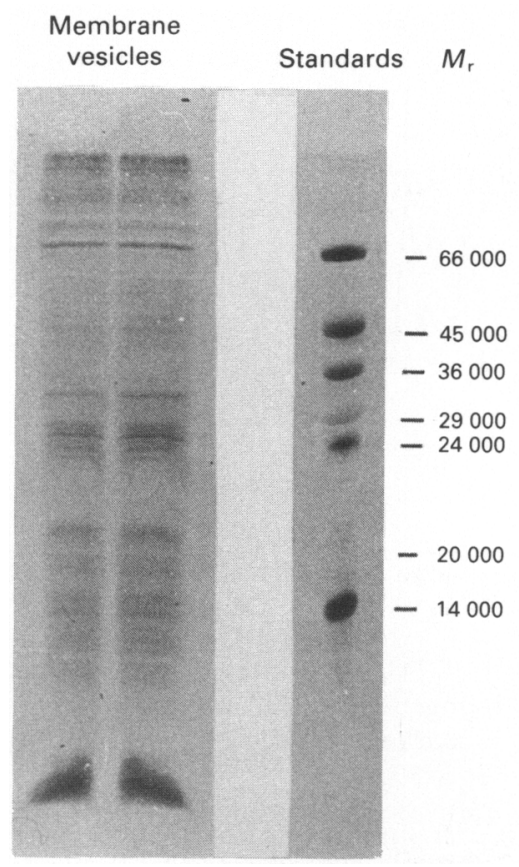

Fig. 6. Silver-stained gels of membrane vesicle preparation, $25 \mu \mathrm{g}$ protein per track.

Table 1. Examples of repeated analyses on the capacity of $\gamma$-globulin fractions from anti-sperm antisera to stimulate or suppress sperm-oocyte fusion

\begin{tabular}{lccc}
\hline & & \multicolumn{2}{c}{ Penetration rate (\%) } \\
\cline { 3 - 4 } Activity & Sample no. & Control & Treated \\
\hline Stimulatory & 8253 & 6 & 20 \\
& & 60 & 92 \\
Inhibitory & 8699 & 83 & $12-5$ \\
& & 60 & 6 \\
& 8751 & 83 & $5 \cdot 3$ \\
& & 60 & 0 \\
& 8000 & 80 & 0 \\
& & 60 & 6 \\
\hline
\end{tabular}

fuse with the vitelline membrane of the oocyte. Western blot analysis was then used to correlate the biological activity of the antisera with the nature of the sperm surface components targeted by the antibodies.

The influence of the $\gamma$-globulin fractions obtained from the sera of 61 patients on the frequency of sperm-oocyte fusion is illustrated in Fig. 4. A majority of these samples exhibited an inhibitory effect on sperm-oocyte interaction although the degree of suppression observed varied considerably between samples. In contrast, $21 \%$ of the samples examined exhibited a variable ability to enhance the levels of sperm-oocyte fusion observed, in response to the calcium signal generated by A23187. These suppressive/stimulatory properties exhibited by the individual $\gamma$-globulin preparations were repeatable (see examples in Table 1), were achieved without any significant changes 

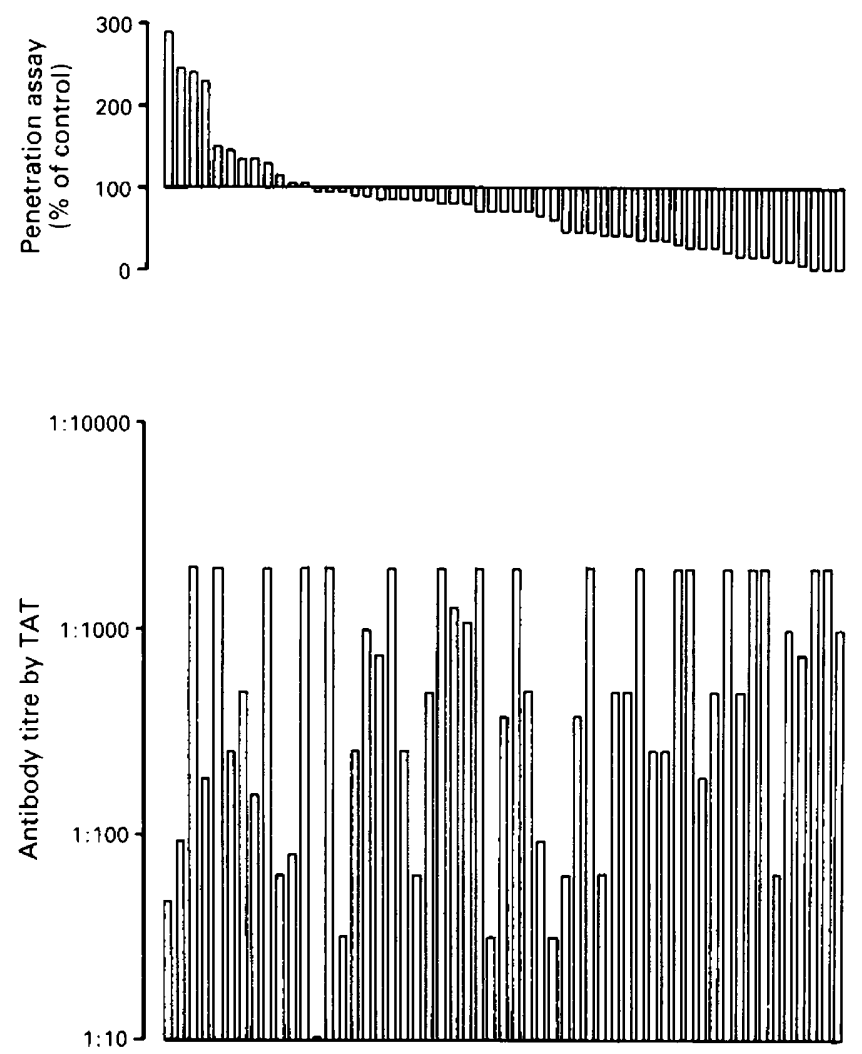

Fig. 7. Influence of the $\gamma$-globulin fraction of anti-sperm antisera of infertile patients on spermoocyte fusion compared to the antibody titres given by the tray agglutination test (TAT).

in the motility of the spermatozoa, and were not correlated with the antibody titres as measured by the Tray agglutination test (Fig. 7), immunobead binding or the ability of the antisera to influence cervical mucus penetration (data not shown).

Western blot analysis also revealed little correlation between the ability of a sample to influence sperm-oocyte fusion and the nature of the proteins targeted in the plasma membrane. Representative blots from samples showing a range of activity in the suppression or activation of sperm-oocyte fusion are illustrated in Fig. 8(a). The results revealed that these antisera targeted a variable number of high molecular weight $\left(M_{\mathrm{r}}>30000\right)$ components on the plasma membrane, many of which exhibited $M_{\mathrm{r}}$ values similar to components of the sperm surface identified in the surface labelling studies $\left(M_{\mathrm{r}}=35000,45000,66000,90000\right.$ and 115000). Of these components the band with an $M_{\mathrm{r}}$ value of 90000 was most heavily bound by most of the antisera tested.

To determine whether these antisera might also be targeting internal antigens or antigens which might have been removed in the process of isolating the membrane fraction, the Western blot studies were repeated on deoxycholate extracts of intact spermatozoa. The results of this study, presented in Fig. 8(b), again revealed that the antisera were targeting high molecular weight components $\left(M_{\mathrm{r}}>30000\right)$, including the major surface antigens with $M_{\mathrm{r}}$ values of 30000,45000 , 66000 and 90000 . Additional bands with $M_{\mathrm{r}}$ values of 50000,57000 and a dominant component at 102000 presumably represent internal antigens which had been released by the deoxycholate treatment. Once again there appeared to be little relationship between the Western blotting patterns and the ability of the antisera to influence sperm-oocyte fusion. 


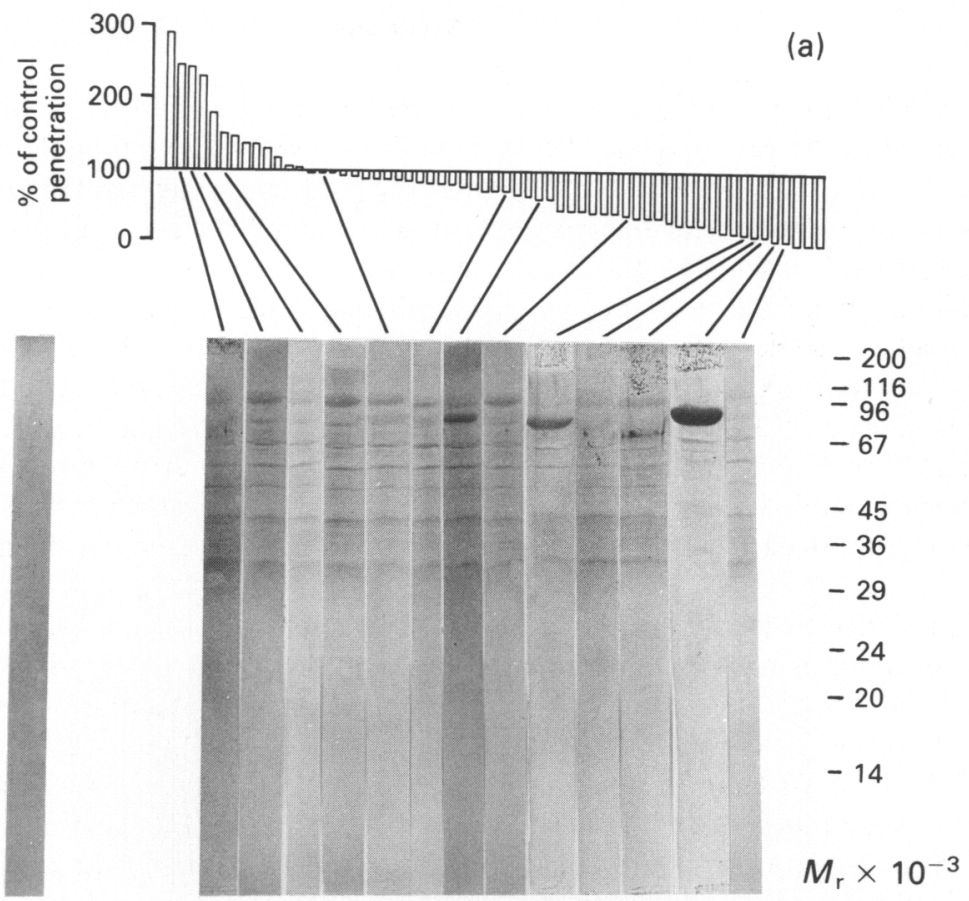

Control

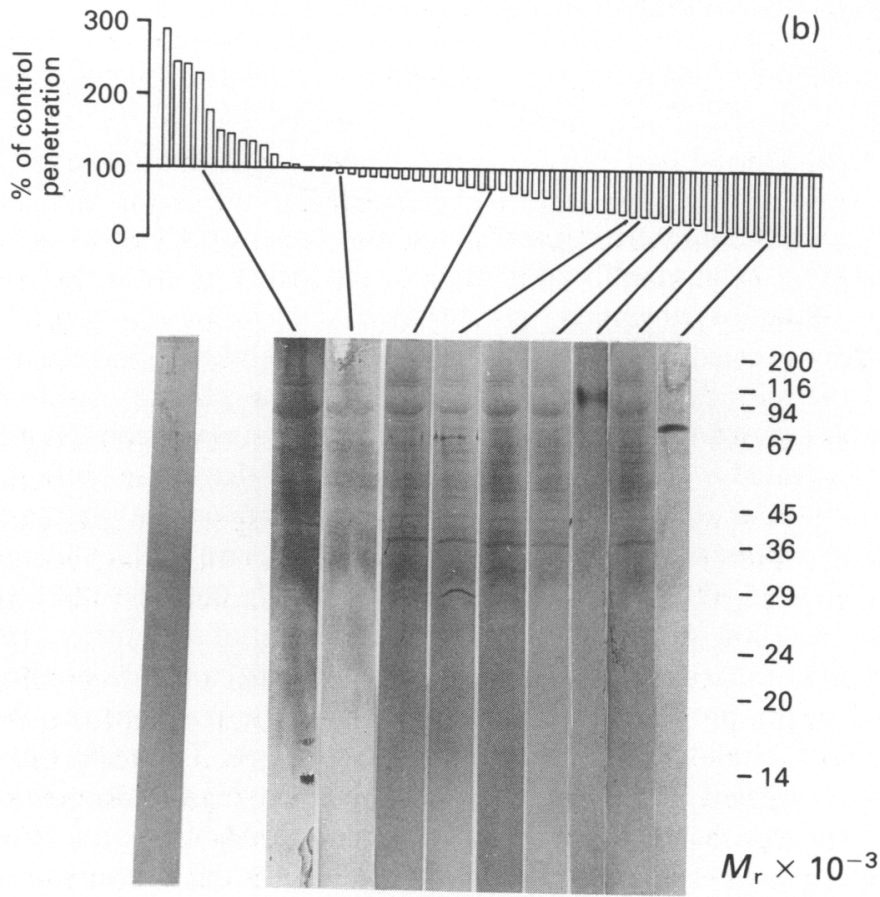

Fig. 8. Representative Western blots of antisera showing a range of activity in the zona-free hamster egg penetration tests: (a) isolated membrane fraction, and (b) deoxycholate extract of intact cells. 


\section{Discussion}

The surface labelling patterns obtained with human spermatozoa in this study are very similar to those observed in the rat by Klinefelter \& Hamilton (1985) in revealing 2 major peaks of radioactivity, one with an $M_{\mathrm{r}}$ of around 23000 and a second migrating just behind the ion front. This leading peak was extractable with chloroform and methanol or ether, suggesting a lipid-like constitution. The equivalent fraction on the rat sperm plasma membrane has been definitively identified as a glycolipid (Klinefelter \& Hamilton, 1985) while a major antigen on the surface of guinea pig spermatozoa has also been shown to possess properties consistent with a glycolipid (Teuscher $e t$ al., 1982). The second peak with an $M_{\mathrm{r}}$ value of 20-24000 could be precipitated with TCA and was specifically labelled with galactose oxidase- $\mathrm{NaB}\left[{ }^{3} \mathrm{H}\right]_{4}$ treatment, suggesting that this component is glycoprotein. The $M_{\mathrm{r}} 24000$ component on the rat sperm surface is also labelled with this technique and has been identified as an $\alpha$-lactalbumin-like glycoprotein, which is normally present on the surface of spermatozoa from the cauda but not the caput epididymidis (Klinefelter \& Hamilton, 1985).

The function of $\alpha$-lactalbumin on the surface of the mammalian spermatozoon is currently unknown although it has been speculated that this complex is involved in modifying the carbohydrate structure of the sperm surface (Hamilton, 1981), possibly conferring upon the spermatozoa the ability to recognize the zona pellucida. Recent studies by O'Rand et al. (1985) have shown that heat-solubilized, iodinated human zonae pellucidae bind specifically to two major peptides derived from human spermatozoa with $M_{\mathrm{r}}$ values of 17000 and 18000 , together with a minor component at $M_{\mathrm{r}}=15000$. It is possible that these components correspond to the major doublet of bands observed in the surface labelling studies with $M_{\mathrm{r}}$ values of 17000 and 19000 , together with the minor band at 15000 . The small difference in molecular weights is possibly due to differences in the conditions used for electrophoresis or microheterogeneity in the molecular weights due to different degrees of glycosylation (Hamilton, 1981).

The only other formal study of the surface labelling patterns given by human spermatozoa was undertaken by Young \& Goodman (1980). The electrophoretic profile described by these workers, with 5 even peaks of radioactivity with molecular weights ranging from $M_{\mathrm{r}}=20000$ to $M_{\mathrm{r}}=92000$ appears quite unlike the patterns described in this paper and at present we cannot explain these differences. Although the molecular weights ascribed to the major constituents of the human sperm surface by Young \& Goodman (1980) do resemble some of the values presented here (the bands with $M_{\mathrm{r}}$ values of $92000,72000,46000,30000$ and 20000 described by these authors could be equated with the components at $115000,66000,40-45000,30000$ and 19000 identified in this study) the distribution of radioactivity is different and none of the minor components described by us were recorded.

The isolation of a membrane-rich fraction from human spermatozoa was achieved following a protocol previously described by Gillis et al. (1978), with the exception that short bursts of ultrasonication rather than nitrogen cavitation were used to disrupt the spermatozoa. The end result appears to be similar, however, with the isolation of a homogeneous population of vesicles from the sucrose gradients exhibiting ultrastructural features, and an electrophoretic profile, characteristic of the plasma membrane.

These membrane preparations were subsequently used to examine the nature of the surface antigens targeted by anti-sperm antisera, which had previously been assessed for their ability to influence sperm-oocyte fusion in vitro. The antisera revealed an unexpected ability to stimulate or inhibit the levels of sperm-oocyte fusion observed after the induction of the acrosome reaction with A23187. We have previously reported (Dor et al., 1981) that antisera from the World Health Organization's serum bank exhibit a variable capacity to suppress the levels of sperm-oocyte fusion observed in a system lacking A23187. In contrast, Bronson et al. (1981) have recorded the stimulation of gamete fusion when anti-sperm antisera were added to their zona-free hamster egg system. The findings reported in this study resolve these differences by indicating that populations of both 
inhibitory and stimulatory antisera exist within the cohort of patients exhibiting idiopathic autoimmunity. We have also observed the presence of stimulatory and inhibitory antibodies in the seminal plasma of patients exhibiting autoimmunity following vasovasostomy (data not presented). The existence of inhibitory antisera was anticipated and presumably reflects the presence of antibodies capable of masking those surface determinants on the acrosome-reacted human spermatozoon capable of recognizing and initiating fusion with the vitelline membrane of the oocyte. The presence of stimulatory antibodies is more difficult to explain. One exciting possibility is that $\gamma$-globulin preparations exhibiting this activity contain antibodies which are able to cross-link, and thence activate, receptor sites on the human sperm surface which are capable of initiating those biochemical events normally responsible for inducing membrane fusion and which, in physiological circumstances, interact with complementary receptors on the zona surface (Singer et al., 1985). The ability of anti-receptor antibodies to induce cell activation in other cell types is well established; antibodies against the insulin receptor, for example, are known to induce the spectrum of biochemical changes associated with the action of insulin itself (Zick et al., 1984).

The ability of the $\gamma$-globulin preparations to stimulate or inhibit sperm-oocyte fusion bore no relationship to any of the other biological and immunological properties measured for these samples. When the isolated membrane fraction was used as substrate, most samples appeared to exhibit a preferential affinity for a band exhibiting an $M_{\mathrm{r}}$ value of 90000 corresponding to one of the minor components of the sperm surface identified in the surface labelling studies. Analysis of the sperm antigens binding to antisera from the World Health Organization's serum bank by Lee $e t$ al. (1983) also recorded a high frequency of samples containing antibodies directed against a 90000 molecular weight component. The presence of a high proportion of antisera possessing antibodies against surface components exhibiting $M_{\mathrm{r}}$ values of around 35000 and 45000 is also in keeping with previous studies (Poulson \& Hjort, 1981; Czuppon et al., 1981; Naaby-Hansen \& Bjerrum, 1985), although the 14000 molecular weight antigen targeted by the antisera examined by Lehmann et al. (1985) was not observed in our study. The lack of a direct correlation between the nature of the bands targeted and the ability of a given antiserum to enhance or suppress sperm-oocyte fusion may simply reflect the fact that these antisera contain a complex mixture of antibodies with differing, possibly conflicting, biological activities, some of which have not been assessed by the bioassays used in this study. Such studies emphasize that ascribing defined biological roles to specific membrane components will only be possible when an appropriate range of monoclonal antibodies has been prepared against the major antigens presented on the surface of human spermatozoon.

We thank Ms Jane Clarkson and Mr David Richardson for their invaluable assistance in the course of this project.

\section{References}

Aitken, R.J. (1982) The contraceptive potential of antisperm antibodies. In Progress towards a Male Contraceptive, pp. 109-134. Eds S. L. Jeffcoate \& M. Sandler. John Wiley \& Sons, Chichester.

Aitken, R.J., Holme, E., Richardson, D.W. \& Hulme, M. (1982) Properties of intact and univalent (Fab) antibodies raised against isolated, solubilized, mouse zonae pellucidae. J. Reprod. Fert. 66, 327-334.

Aitken, R.J., Ross, A., Hargreave, T., Richardson, D. \& Best, F. (1984) Analysis of human sperm function following exposure to the ionophore A23187. Comparison of normospermic and oligozoospermic men. $J$. Androl. 5, 321-329.

Aitken, R.J., Sutton, M., Warner, P. \& Richardson, D.W. (1985) Relationship between the movement charac- teristics of human spermatozoa and their ability to penetrate cervical mucus and zona-free hamster oocytes. J. Keprod. Fert. 73, 441-449.

Ashraf, M., Peterson, R.N. \& Russell, L.D. (1982) Activity and location of cation-dependent ATPases on the plasma membrane of boar spermatozoa. Biochem. Biophys. Res. Commun. 107, 1273-1278.

Biggers, J.D., Whitten, W.K. \& Whittingham, D.G. (1971) The culture of mouse embryos in vitro. In Methods in Mammalian Embryology, pp. 86-116. Ed. J. C. Daniel, Jr. Freeman, San Francisco.

Bradley, M.P. \& Forrester, I.T. (1980) A $\left(\mathrm{Ca}^{2+}+\mathrm{Mg}^{2+}\right)$ ATPase and active $\mathrm{Ca}^{2+}$ transport in the plasma membranes isolated from ram sperm flagella. Cell Calcium 1, 381-390. 
Breitbart, H. \& Rubinstein, S. (1983) Ca transport by bull spermatozoa plasma membranes. Biochim. Biophys. Acta 732, 464-468.

Bronson, R., Cooper, G. \& Rosenfeld, D. (1981) Ability of antibody-bound human sperm to penetrate zona-free hamster ova in vitro. Fert. Steril. 36, 778-783.

Czuppon, A.B., Mettler, L., Schauer, R. \& Pawassarat, V. (1981) Purification of a human spermatozoal antigen. Hoppe-Seyler's Z. Physiol. Chem. 362, 963-968.

Dor, J., Rudak, E. \& Aitken, R.J. (1981) Antisperm antibodies: their effect on the process of fertilization studied in vitro. Fert. Steril. 35, 535-541.

Ebenshade, K. \& Clegg, E.D. (1980) Surface proteins of ejaculated porcine sperm and sperm incubated in the uterus. Biol. Reprod. 23, 530-537.

Fraker, P.J. \& Speck, J.C. (1978) Protein and cell membrane iodinations with a sparingly soluble chloroamide, 1,3,4,6-tetrachloro 3,6-diphenylglycoluril. Biochem. Biophys. Res. Commun. 80, 849-857.

Friberg, J. (1974) A simple and sensitive micro-method for demonstration of sperm agglutinating antibodies in serum from infertile men and women. Acta obstet. gynaecol. scand. (Suppl.) 36, 21-29.

Gahmberg, C.G. \& Hakomori, S. (1973) External labelling of cell surface galactose and galactosamine in glycolipid and glycoprotein of human erythrocytes. J. biol. Chem. 248, 4311-4317.

Gillis, G., Peterson, R. \& Russell, L. (1978) Isolation and characterization of membrane vesicles from human and boar spermatozoa: methods using nitrogen cavitation and ionophore induced vesiculation. Prep. Biochem. 8, 363-378.

Hamilton, D.W. (1981) Evidence for $\alpha$-lactalbumin-like activity in reproductive tract fluids of the male rat. Biol. Reprod. 25, 385-392.

Jager, S., Kremer, J. \& van Slochteren-Draaisma, T. (1978) A simple method of screening for antisperm antibodies in the human male. Int. J. Fertil. 23, $12-21$.

Katz, D.F., Overstreet, J.W. \& Hanson, F.W. (1980) A new quantitative test for sperm penetration into cervical mucus. Fert. Steril. 33, 179-186.

Klinefelter, G.R. \& Hamilton, D.W. (1985) Synthesis and secretion of proteins by perifused caput epididymal tubules and association of secreted proteins with spermatozoa. Biol. Reprod. 33, 1017--1027.

Laemmli, U.K. (1970) Cleavage of structural proteins during the assembly of the head of bacteriophage T4. Nature, Lond. 227, 680-685.

Lee, C-Y.G., Huang, Y-S., Hu, P-C., Gomel, V. \& Menge, A.C. (1982) Analysis of sperm antigens by sodium dodecyl sulfate gel/protein blot radioimmuno binding method. Analyt. Biochem. 123, 1422.

Lee, C-Y.G., Lum, V., Wong, E., Menge, A.C. \& Huang, Y-S. (1983) Identification of human sperm antigens to antisperm antibodies. Am. J. Reprod. Immunol. 3, $183-187$

Lehmann, D., Temminck, B., Da Rugna, D., Leibundgut, B. \& Muller, H. (1985) Blot-immunobinding test for the detection of anti-sperm antibodies. $J$. Reprod. Immunol. 8, 329-336.

Lowry, O.H., Rosebrough, N.J., Farr, A.L. \& Randall, R.J. (1951) Protein measurements with the Folinphenol reagent. J. biol. Chem. 193, 265-275.

Markwell, M.A.K. \& Fox, C.F. (1978) Surface specific iodination of membrane proteins of viruses and eucaryotic cells using 1,3,4,6,-tetrachloro-3,6-diphenylglycoluril. Biochemistry, N.Y. 17, 4807-4817.

Naaby-Hansen, S. \& Bjerrum, O.J. (1985) Auto- and iso-antigens of human spermatozoa detected by immunoblotting with human sera after SDS-PAGE. J. Reprod. Immunol. 7, 41-57.

O'Rand, M.G. (1977) Restriction of a sperm surface antigen's mobility during capacitation. Devl Biol. 55, 260-270.

O'Rand, M.G., Matthews, J.E., Welch, J.E. \& Fisher, S.J. (1985) Identification of zona binding proteins of rabbit, pig, human and mouse spermatozoa on nitrocellulose blots. J. exp. Zool. 235, 423-428.

Poulsen, F. \& Hjort, T. (1981) Identification of auto antigens of the human sperm membrane. J. clin. lab. Immunol. 6, 69-74.

Saling, P.M. (1982) Development of the ability to bind to the zona pellucida during epididymal maturation: reversible immobilization of mouse spermatozoa by lanthanum. Biol. Reprod. 26, 429-436.

Shur, B.D. \& Hall, N.G. (1982) A role for mouse sperm surface galactosyl transferase in sperm binding to the egg zona pellucida. J. Cell Biol. 95, 574-579.

Silvestroni, L., Sartori, C., Modesti, A. \& Frajese, G. (1980) Preparation of pure fractions of human sperm membranes. Archs Androl. 4, 221-230.

Singer, S.L., Lambert, H., Overstreet, J.W., Yanagimachi, R. \& Hanson, F.W. (1985) The kinetics of human sperm binding to the human zona pellucida and zona-free hamster oocyte in vitro. Gamete Res. 12, 29-39.

Steck, T.L. \& Dawson, G. (1974) Topographical distribution of complex carbohydrates in the erythrocyte membrane. J. biol. Chem. 249, 2135-2142.

Teuscher, C., Wild, G.C. \& Tung, K.S.K. (1982) Immunochemical analysis of guinea pig sperm autoantigens. Biol. Reprod. 26, 218-229.

Towbin, H., Staehelin, T. \& Gordon, J. (1979) Electrophoretic transfer of proteins from polyacrylamide gels to nitrocellulose sheets: procedure and some applications. Proc. natn. Acad. Sci. U.S.A. 76, $4350-4354$

Voglmayr, J.K., Fairbanks, G., Jackowitz, M.A. \& Colella, J.R. (1980) Post-testicular developmental changes in the ram sperm cell surface and their relationship to luminal fluid proteins of the reproductive tract. Biol. Reprod. 22, 655-667.

Yanagimachi, R. (1981) Mechanisms of fertilization in mammals. In Fertilization and Embryonic Development in Vitro, pp. 81-182. Eds L. Mastroianni, Jr \& J. D. Biggers. Plenum, New York.

Yanagimachi, R., Yanagimachi, H. \& Rogers, B.J. (1976) The use of zona-free animal ova as a test system for the assessment of fertilizing capacity of human spermatozoa. Biol. Reprod. 15, 471-476.

Young, L.G. \& Goodman, S.A. (1980) Characterization of human sperm cell surface components. Biol. Reprod. 23, 826-835.

Zick, Y., Rees-Jones, R.W., Taylor, S.I., Gorden, P. \& Roth, J. (1984) The role of antireceptor antibodies in stimulatory phosphorylation of the insulin receptor. J. biol. Chem. 259, $4396-4400$.

Received 2 October 1986 